\title{
A DESIGNAÇÃO DO NOME LÓCUS DE FORMAÇÃO CONTINUADA NOS PARECERES ORIENTATIVOS DA SEDUC/MT
}

\author{
Eliane Cristina Dalcico* \\ UNEMAT \\ Neuza Zattar** \\ UNEMAT
}

Resumo: Propomos analisar, por meio deste artigo, sob a perspectiva da Semântica do Acontecimento (GUIMARÃES, 1992, 1999, 2005, entre outros), o processo de designação do nome lócus de formação continuada que aparece inscrito nos documentos Pareceres Orientativos, produzidos pela Secretaria de Estado de Educação de Mato Grosso/SEDUC/MT. Observamos como a linguagem constrói relações com o mundo, mas que não se reduz ao referi-lo. Nesse sentido, vamos examinar como em cada nome os elementos a que ele se refere são identificados simbolicamente. A designação dada ao nome lócus de formação continuada nos Pareceres Orientativos da SEDUC/MT mostra que é um espaço político, constituído de línguas que funcionam na sua relação com os falantes, que é significado enunciativamente pela instituição SEDUC/MT e a Superintendência de Formação dos Profissionais da Educação/SUFP que os organiza.

Palavras-chave: Designação, Lócus de formação continuada, Espaço político.

Abstract: We propose to analyze, through this paper, in the perspective of Semantics of the Events (GUIMARÃES, 1992, 1999, 2005, among others), the process of designation of the name locus of continuous formation that come to light inscribed in the Guiding Notions documents, produced by the Secretaria de Estado de Educação de Mato Grosso (State Secretary of Education of Mato Grosso)/SEDUC/MT. We can observe how language builds relations with the world, but that not reduced by referring it. In this perspective, we will examine how in each name the elements they refer are 
symbolically identified. The designation given to the name locus of continuous formation in the SEDUC / MT Guidance Notions indicate that it is a political space, composed by languages that work in their relationship with the speakers, and is implied by the SEDUC / MT institution and the Training Superintendence of Education Professionals / SUFP that organizes them.

Keywords: Designation, Locus of continuous formation, Political space.

\section{Introdução}

O estudo da significação tem instigado os estudiosos da linguagem que, ao desenvolverem determinadas teorias, tomam a significação distinta de sentido. Um dos autores que faz essa distinção é Ducrot (1987), ao tratar da frase ${ }^{1}$ e do enunciado. Ao nos depararmos com os estudos sobre a significação surgem questões como: o que é sentido? O que é significação? O sentido está na palavra? Por que os sentidos das palavras mudam? Como se atribuem os sentidos? Entre outras questões.

Neste trabalho, não podemos deixar de citar Frege (1892), cujos estudos sobre significado, sentido e referência exerceram grande influência sobre os estudos da significação da/na linguagem, e também Michel Bréal que, em 1897, publica "Ensaio de Semântica", com o qual funda a Semântica, "contribuindo para repor à reflexão a questão do sentido e da história” (GUIMARÃES, 1992, p. 09).

Outra questão importante é o corte saussuriano, que excluiu dos estudos da língua o mundo, o sujeito e a história, por tratar a língua somente no seu funcionamento interno. Os autores Haroche, Henry e Pêcheux, em La Sémantique et la Coupure Saussurienne: Langue, Langage, Discours, salientam que, do ponto de vista linguístico saussuriano, o valor domina o significado (HAROCHE; HENRY; PÊCHEUX, 1971, p. 96). Ou seja, o significado só pode funcionar no interior do sistema linguístico. A partir desse lugar teórico, os autores problematizam a relação valor/significado e pensam uma "semântica discursiva" introduzindo no seu interior conceitos do materialismo histórico, constituindo um nouveau terrain théorique (HAROCHE; HENRY; PÊCHEUX, 1971, p. 102).

Nas últimas décadas, autores como Benveniste, Ducrot, Guimarães, dentre outros, têm procurado incluir os elementos 
excluídos por Saussure nos estudos da linguagem que desenvolvem(ram). É, então, a partir de Frege que Guimarães (2010), pelo modo de considerar o sentido, se propõe a relacionar a referência de outra maneira. Ao identificar a exclusão da exterioridade da língua ${ }^{2}$ como um problema para tratar de questões importantes para a significação, o autor, em sua Semântica do Acontecimento (2005), trata a relação entre sentido e referência de modo diferente de Frege, uma vez que a sua semântica não se fundamenta em princípios lógicos, mas em princípios enunciativos fundamentados no materialismo histórico. Para o semanticista (GUIMARÃES, 2010), é a inclusão da história nos processos enunciativos que determinam a significação. Conforme o autor, a "construção desta concepção se faz para nós na medida em que consideramos que o sentido deve ser tratado como discursivo e definido a partir do acontecimento enunciativo" (GUIMARÃES, 2010, p. 66).

Desse modo, a referência é tomada pelo semanticista como:

[...] um objeto perceptível e o sentido é o modo de apresentar um objeto enquanto a serviço, de modo igual, daqueles que falam uma língua dada. Esta mesma distinção é considerada relativamente às sentenças. As sentenças têm como sentido o pensamento que expressam e como referência seu valor de verdade (GUIMARÃES, 2010, p. 27).

Nessa via de considerações, faz-se necessário dizer que a relação entre sentido e referência é tratada por Guimarães a partir da noção de designação que será definida mais a frente.

Assim, neste trabalho, diferentemente da proposição de Frege em relação ao sentido, propomos analisar, na perspectiva da Semântica do Acontecimento, o processo de designação do nome lócus de formação continuada que aparece inscrito nos documentos Pareceres Orientativos, produzidos pela Secretaria de Estado de Educação de Mato Grosso/SEDUC/MT, observando como a linguagem constrói relações com o mundo, mas que não se reduz ao referi-lo. Nesse sentido, vamos examinar como em cada designação do nome lócus de formação continuada, os elementos a que ele se remete são identificados simbolicamente de forma distinta. 
Nessa perspectiva, este trabalho se constituirá de dois momentos: mobilizaremos a compreensão de enunciação proposta por Guimarães (2005), a partir da noção de acontecimento enunciativo, para observar como essa noção desloca os sentidos das categorias de pessoa, espaço e tempo: para a categoria de pessoa especificaremos as noções de falante, agenciamento enunciativo e cena enunciativa; para a categoria de espaço o de espaço enunciativo e o político; em relação à categoria de tempo consideraremos o presente, o passado memorável e a latência de futuro da temporalidade do acontecimento.

Interessa-nos também ver como o autor compreende o real, a relação entre texto, enunciado e designação, referência e nomeação. $\mathrm{E}$, posteriormente, vamos analisar a designação do nome lócus de formação continuada nos documentos Pareceres Orientativos produzidos pela Secretaria de Estado de Educação de Mato Grosso (SEDUC/MT), enviados todos os anos no início do período letivo às escolas públicas estaduais.

Os documentos são os seguintes: Pareceres Orientativos de 2010, 2011, 2017 e 2018. Esses documentos reúnem diversas orientações aos profissionais da educação e determinam o funcionamento da formação continuada na unidade escolar durante todo o ano letivo.

No item seguinte, vamos situar brevemente a instituição da formação de professores do ensino fundamental nas unidades escolares em Mato Grosso sócio-historicamente.

\section{A questão da formação de professores}

A política nacional de formação de professores é articulada em duas dimensões, Formação Inicial (FI) e Formação Continuada (FC) e acolhe os princípios estabelecidos na Constituição Federal, na Lei de Diretrizes e Bases da Educação Nacional (LDB), no Plano Nacional de Educação (PNE) e na Resolução $\mathrm{CNE} / \mathrm{CP} \mathrm{n}^{\circ} 2$, de $1^{\circ}$ de julho de 2015.

No estado de Mato Grosso, a formação continuada é produzida pela Secretaria de Estado de Educação (SEDUC/SUFP ${ }^{3}-\mathrm{MT}$ ), que prevê, além de momentos isolados de estudo, palestras e cursos pontuais, a integração entre escola, currículo, ensino e professor. Em cumprimento a essa política, foram criados os Centros de Formação dos Profissionais da Educação Básica (CEFAPROs) ${ }^{4}$ em cada município-polo do estado. 
O projeto de formação continuada é concebido em Mato Grosso em 2003 como:

'Sala de Professor' tinha, em sua gênese, um comprometimento com a formação continuada dos docentes. Esse espaço de formação foi ganhando corpo ao longo dos anos com a participação dos profissionais que atuam nas escolas, levando-nos a repensar esse espaço formativo não mais como do 'professor', mas como de todo aquele que trabalha na escola [...] (MATO GROSSO, 2010a, p. 23).

Apresentaremos, no próximo item, conceitos da Semântica do Acontecimento que sustentarão, posteriormente, nossas análises.

\section{Alguns conceitos da Semântica do Acontecimento}

A Semântica do Acontecimento, proposta por Guimarães, "considera que a análise do sentido da linguagem deve localizar-se no estudo da enunciação, do acontecimento do dizer" (GUIMARÃES, 2005, p. 07). Desse modo, é pela enunciação que os sentidos são produzidos por meio do funcionamento da língua no espaço de enunciação.

Propomos, então, um percurso para compreendermos a enunciação e a partir da noção de acontecimento, observar como essa noção desloca os sentidos das categorias enunciativas de pessoa, espaço e tempo.

Ao entendermos que a língua funciona no acontecimento pela assunção da palavra, uma cena enunciativa "se caracteriza por constituir modos específicos de acesso à palavra dadas as relações entre as figuras da enunciação e as formas linguísticas" (GUIMARÃES, 2005, p. 23). Para o semanticista (2005), a cena enunciativa se caracteriza por constituir lugares enunciativos singulares que se configuram em agenciamento enunciativo para 'aquele que fala' e 'aquele para quem se fala', ou seja, não são as pessoas donas do seu dizer, mas os lugares constituídos pelos dizeres é que caracterizam a cena enunciativa.

Desse modo, Guimarães (2005) considera alguns aspectos relevantes no modo de constituição destes lugares pelo funcionamento 
da língua. Primeiro, a distribuição de lugares acontece pela temporalização própria do acontecimento. Assumir a palavra é colocar-se no lugar que enuncia, e o autor o define como lugar do Locutor (L), que se representa no próprio dizer como origem deste dizer. Mas, para dizer do lugar de Locutor é preciso estar afetado pelos lugares sociais (Locutor-x), autorizado a falar de um determinado modo e por uma determinada língua.

Outro aspecto importante é a constituição da cena enunciativa de lugares sociais de locutor e de outros lugares de dizer. Guimarães (2005) apresenta quatro tipos de enunciadores: o enunciadorindividual como aquele que está acima de todos e representa a linguagem como independente da história; o enunciador-genérico é aquele que apaga o lugar social e o que se diz é dito com todos os outros; enunciador coletivo é o que diz em nome de todos; e o enunciador universal representa o Locutor como fora da história e é dependente do verdadeiro e do falso. Os enunciadores se caracterizam pela inexistência dos lugares sociais de Locutor.

Partindo desse pressuposto, a relação entre a língua e o falante é tomada não pela relação empírica, mas enquanto espaço regulado que impõe a divisão do poder dizer e como dizer.

Nessa direção, considerando a categoria de espaço, o espaço de enunciação é o "espaço de relações de línguas no qual elas funcionam na sua relação com os falantes" (GUIMARÃES, 2018a, p. 23). Sem embargo, o autor afirma que as línguas do espaço de enunciação não são distribuídas de modo igual, pois os falantes das línguas deste espaço não o são da mesma maneira. Portanto, não é uma simples relação empírica.

A configuração das cenas nos espaços de enunciação caracteriza-se num espaço político do funcionamento das línguas, pois nele se realiza a relação entre línguas e falantes, a exterioridade da língua, sua historicidade. Desse modo:

Este aspecto se projeta na cena pelo modo como se divide o falante ao ser agenciado a falar. Nesta divisão se apresenta um enunciador como certo eu daquilo que se diz. Ao mesmo tempo esta divisão institui para o Locutor e para $\mathrm{o}$ alocutor- $\mathrm{x}$ 
um tu (um Locutário, num caso, e um alocutário, em outro) (GUIMARÃES, 2018a, p. 62).

Com isso, o semanticista mostra que no funcionamento enunciativo o agenciamento é histórico, pois existe uma particularidade do espaço de enunciação onde se organiza a relação entre línguas e falantes. E no acontecimento enunciativo ocorre uma divisão do falante pela relação de alocução (lugar que diz e lugar social de dizer) que se apresenta como Locutor/Locutário e alocutor-x/alocutário-x.

Há, portanto, nos diversos espaços de enunciação o funcionamento de línguas que determinam os falantes pelas línguas que falam. Para Guimarães (2005), nesse espaço de enunciação, que é também um espaço político (espaço da contradição), é que a língua se divide formando nesse espaço uma hierarquia de identidades. Esta hierarquia se define pelo agenciamento de quem pode dizer determinadas coisas e não outras, falar de determinados lugares de Locutor e não de outros, a ter determinados interlocutores e não outros.

Ainda uma terceira categoria enunciativa é importante para a compreensão da enunciação: o tempo. A temporalidade do acontecimento para o autor:

[...] constitui o seu presente e um depois que abre o lugar dos sentidos, e um passado que não é lembrança ou recordação pessoal de fatos anteriores. O passado é, no acontecimento, rememoração de enunciações, ou seja, se dá como parte de uma nova temporalização, um novo espaço de conviviabilidade de tempos, sem a qual não há sentido, não há acontecimento de linguagem, não há enunciação (GUIMARÃES, 2005, p. 12).

Nessa acepção, acontecimento e temporalidade não se separam, e o locutor quando enuncia está atravessado por uma memória que é constitutiva do seu dizer, ou seja, o falante ao enunciar é capturado na temporalidade do acontecimento. Nessa perspectiva, a temporalidade do acontecimento "não coincide, portanto, com o tempo do ego que diz eu" (GUIMARÃES, 2005, p. 14). Porém, para o semanticista (2005) ela se conforma por um presente que se projeta em si uma 
latência de futuro, necessária para o acontecimento de linguagem e da significação.

\subsection{Nomeação/renomeação, designação e referência}

Considerando que nosso trabalho se propõe a ver como são significadas as designações do nome lócus de formação continuada, torna-se pertinente apresentar as noções de nomeação, renomeação, designação e referência, na perspectiva enunciativa da Semântica do Acontecimento.

No que se refere à nomeação, Guimarães (2005) a define como "o funcionamento semântico pelo qual algo recebe um nome" (p. 09); a renomeação "se dá como produzida pelo modo como um grupo social específico (família, escola, grupo profissional, etc.) opera sobre o nome inicial" (GUIMARÃES, 2018a, p. 201); a designação, para o autor (2005), "é o que se poderia chamar de significação de um nome" (p. 09). Assim, um nome refere algo porque designa algo "enquanto uma relação linguística (simbólica) remetida ao real, exposta ao real, ou seja, enquanto uma relação tomada na história" (GUIMARÃES, 2005, p. 09).

Parafraseando Guimarães (2005), a designação é a significação do nome, enquanto algo próprio das relações de linguagem. Aquilo que pode recortar o real de alguma maneira. Relação simbólica, não ontológica, que se reporta ao real afetado pela história. $\mathrm{O}$ autor concebe o real não na perspectiva da pragmática, como o que está no contexto ou na situação, pois não se enuncia enquanto ser físico ou simplesmente num mundo físico. Mas se enuncia "enquanto ser afetado pelo simbólico e num mundo vivido através do simbólico". (p. 11).

Em relação à designação, Zattar diz que:

[...] um determinado nome recebe uma designação não pelo significado denotativo ou literal de que é constituído, mas pela relação de sentido que estabelece com outros nomes em determinadas condições. Como o processo de designação se movimenta com o funcionamento da língua e dos sujeitos aí instituídos, podemos dizer que as designações dadas pelos nomes 
mudam à medida que os nomes vão constituindo novos significados (ZATTAR, 2012, p. 03).

Relacionada à designação está a referência. Guimarães define a referência "como uma particularização de algo na e pela enunciação." (GUIMARÃES, 2005, p. 09). Para o autor, só podemos referir a uma palavra, nome ou expressão porque está significado, porque se constitui nas relações entre mundo e linguagem. Referir é especificar algo único. A referência é feita, na medida em que se faz a designação.

Como o corpus deste trabalho é constituído de textos institucionais, consideramos importante a análise dos procedimentos de reescrituração. Conforme Guimarães, o procedimento de reescrituração é:

[...] uma operação que significa, na temporalidade do acontecimento, o seu presente. A reescrituração é a pontuação constante de uma duração temporal daquilo que ocorre. $\mathrm{E}$ ao reescriturar, ao fazer interpretar algo como diferente de si, este procedimento atribui (predica) algo ao reescriturado (GUIMARÃES, 2005, p. 28).

Como o procedimento de reescrituração produz sentido ao texto, Guimarães (2011) define essa unidade de sentido como a que integra enunciados, que se constituem de sentido por se relacionarem entre si.

Passamos às análises, para compreender como se dá a designação do nome lócus de formação continuada inscrito nos documentos institucionais produzidos pela SEDUC/MT e a Superintendência de Formação dos Profissionais da Educação/SUFP.

\section{Análise}

Como já dissemos anteriormente, os recortes que serão analisados foram extraídos de documentos institucionais, construídos/integrados de vários enunciados que remetem às designações do nome lócus de formação continuada na escola.

Nesse sentido, cabe aqui pensar como as diferentes formas de designar o nome lócus de formação continuada podem ser 
significados. E pelos procedimentos de reescrituração observaremos como a designação desse nome é reescriturada numa descrição que funciona ora por substituição, ora por condensação, ora por definição etc. Vamos às análises.

(R1) A Secretaria de Estado de Educação/Superintendência
de Formação dos Profissionais da Educação SEDUC/SUFP
implantou e implementa o Projeto Sala de Professor, cujo
principal objetivo é fortalecer a escola como lócus de formação continuada, por meio da organização de grupos de estudos que priorizem o comprometimento do coletivo da escola com a melhoria da aprendizagem dos que nela estão (PARECER ORIENTATIVO 2010, s/p, grifo da SEDUC/MT e grifo nosso).

Nesse recorte, podemos observar dois acontecimentos enunciativos distintos que não configuram a mesma cena enunciativa. A primeira cena enunciativa é constituída de um Locutor institucional que, ao ser agenciado, diz do lugar social de Locutário-x, representado pela Secretaria de Estado de Educação; e na segunda cena temos um Locutário-x também institucional, representado pela Superintendência de Formação dos Profissionais da Educação. Ambos os Locutores têm como alocutores os professores que atuam nas unidades escolares do estado de Mato Grosso. Na cena 1, o Locutário-Secretaria de Educação se apresenta como aquele que se responsabiliza pelo que está dito/produzido no documento; e na cena 2, o LocutorSuperintendência se apresenta como o porta-voz da Secretaria de Estado de Educação, que também se responsabiliza, dado o seu lugar social, pela implementação do projeto, ou seja, aquele que se dirige aos alocutores-professores para discutir e fazer cumprir a proposta educacional do Governo.

Nessas cenas de interlocução instala-se o conflito entre os interlocutores, de um lado, os lugares sociais da autoridade da SEDUC, a Secretaria de Estado de Educação e da Superintendência de Formação dos Profissionais da Educação/SUFP que, afetadas pelo memorável dos resultados das avaliações do ensino apresentados pelo MEC, propõe, através do Projeto Sala de Professor, fortalecer a escola como lócus de formação continuada para melhorar a qualidade de ensino; e de outro, os professores que, tomados como 
corresponsáveis pelos resultados não satisfatórios do ensino, se veem obrigados a participar da formação continuada. Ou seja, temos nas duas cenas enunciativas posições conflituosas marcadas pelo direito de propor e pelo dever de cumprir.

Além disso, o recorte nos permite compreender que temos o Locutor que fala do lugar social da SEDUC/MT, que assimila o lugar de enunciador universal, que torna o documento Parecer Orientativo como verdadeiro para todo o território mato-grossense.

No R1, o nome lócus de formação continuada é designado por Projeto Sala de Professor, por significar o lugar escolar, a ambiência, onde ocorre a formação dos profissionais da educação nas unidades escolares, na medida em que se dá como confronto de lugares enunciativos que movimentam a língua.

Em relação ao procedimento de reescrituração ${ }^{5}$ textual-enunciativa, observamos que a expressão Projeto Sala de Professor é reescriturada por condensação pelo pronome relativo cujo.

$\mathrm{O}$ verbo implantou (terceira pessoa do singular do pretérito perfeito) e o verbo implementa (terceira pessoa do singular, do presente do indicativo) trazem como memorável a existência e a continuidade do projeto de formação continuada. Implantou significa que o projeto foi iniciado ou que se promoveu o desenvolvimento de algo. A temporalidade da enunciação que diz sobre o lócus de formação continuada se constitui, projetando uma futuridade, o interpretável ou efeito de sentidos, de que o projeto pode aparecer sob vários nomes, mas mantendo a mesma proposta de formação dos professores e de outros servidores que vivenciam o processo escolar. Nas palavras de Zattar "A relação entre o que se diz e o interpretável requer, para significar, um retorno a uma parte do que já foi enunciado, pois esse imbricamento é necessário para produzir os efeitos (a futuridade) do que se diz" (ZATTAR, 2012, s/p).

(R2) [...] a Secretaria de Estado de Educação/Superintendência de Formação dos Profissionais da Educação implantou e implementa o Projeto Sala de Educador, cujo principal objetivo é fortalecer a escola como lócus de formação continuada, por meio da organização de grupos de estudos que priorizem o comprometimento do coletivo da escola com a 
melhoria da qualidade social da educação" (SEDUC/SUFP/MT

- PARECER ORIENTATIVO 2011, s/p., grifos da SEDUC).

Observamos que no R2 há também dois acontecimentos enunciativos distintos já observados no R1, em que se repetem as figuras enunciativas do Locutor-x, figura enunciativa representada pela instituição governamental (SEDUC), e pela figura enunciativa da instituição também governamental, Superintendência de Formação dos Profissionais da Educação (SUFP).

$\mathrm{Na}$ cena enunciativa desse recorte, o nome lócus de formação continuada é designado por Projeto Sala de Educador. Esta designação significa, ao contrário da designação do R1, amplia a participação dos professores e de todos os servidores engajados no processo da escola, na formação continuada.

É importante destacar que a cena enunciativa do R2 toma como seu alocutário-x professores e funcionários dos quadros Técnico Administrativo Educacional e Apoio Administrativo Educacional, significando a inclusão de todos os que integram o processo escolar.

Guimarães (2018b) considera a designação:

[...] como uma relação com as coisas como produzidas pela significação da linguagem", e acrescenta que "a produção da designação se dá pelo modo como se constitui a alocução no acontecimento de enunciação (GUIMARÃES, 2018b, p. 83).

Observamos que o texto R2 reescritura o texto R1 por substituição, e se diferencia apenas quanto à nomeação da nova designação. Nesse sentido, temos um movimento de sentidos provocados pela mudança da designação por Projeto Sala de Educador. Segundo Zattar:

[...] as designações dadas pelos nomes mudam à medida que os nomes vão constituindo novos significados visto que o processo de designação se movimenta com o funcionamento da língua no acontecimento em que o nome designa (ZATTAR, 2012, s/p). 
Nesse sentido, designar "é constituir significação como uma apreensão do real, que significa na linguagem na medida em que o dizer identifica este real para os sujeitos" (GUIMARÃES, 2005, p. 91).

Conforme o documento Parecer Orientativo (2011), a mudança do nome Projeto Sala de Professor, criado em 2003, para Projeto Sala de Educador em 2011, significa assumir a concepção de que a escola é um espaço educativo, com múltiplas tarefas distribuídas não somente aos professores, mas também aos funcionários do quadro Técnico Administrativo Educacional e de Apoio Administrativo Educacional. Ou seja, essa concepção amplia os sentidos da designação Projeto Sala de Educador, ao incluir todos os agentes que compõem o espaço escolar. Essa designação diz respeito aos diferentes agenciamentos enunciativos nos quais as nomeações se constituem e as designações funcionam.

Na perspectiva da Semântica do Acontecimento, a instabilidade da designação do nome propõe pensar o acontecimento não como um fato novo no tempo, pois sua diferença está em que o acontecimento impõe sua própria temporalidade. E o sujeito, nesse sentido, não temporaliza, mas é tomado na temporalidade do acontecimento. Para Guimarães (2005), a temporalidade é um presente que abre em si uma latência de futuro o que possibilita o interpretável, ou seja, que o nome lócus de formação continuada seja significado também como

\section{Projeto Sala de Educador.}

$\mathrm{Na}$ designação desse nome, o presente e futuro próprios do acontecimento reclamam um passado que os faz significar, pois recorta um passado memorável, o já-dito. Assim, parafraseando Guimarães (2005), a temporalidade do acontecimento propicia ao acontecimento sempre uma nova temporalização, um novo sentido, o acontecimento de linguagem, a enunciação. Tal afirmação confirma que na linguagem o sentido se dá no funcionamento da língua no acontecimento da linguagem.

\section{(R3) SUPERINTENDÊNCIA DE FORMAÇÃO DOS PROFISSIONAIS DA EDUCAÇÃO BÁSICA - Este} Orientativo dispõe sobre a formação continuada de docentes na escola. Em sua organização, os tópicos expõem concepções de formação que fundamentam a ação formativa desencadeada 
pelo projeto; argumentos que buscam sustentar o porquê da formação docente centrada na escola; a formação como direito e como necessidade, exposta com a finalidade de que tal compreensão, por parte dos professores reflita na valorização desse tempo/espaço e, ainda, os procedimentos para a elaboração e o desenvolvimento do Projeto de Formação Docente na Escola (SEDUC/SUFP/MT - PARECER ORIENTATIVO 2017, p. 147, grifo nosso).

Neste recorte, o acontecimento enunciativo configura outra cena enunciativa. O Locutor, ao ser agenciado, diz do lugar social de Locutário-x, representado pela Superintendência de Formação dos Profissionais da Educação, órgão vinculado à Secretaria de Estado da Educação, responsável por fazer cumprir as propostas educacionais do Governo, e o alocutor-x, representando os professores da educação de Mato Grosso que atuam nas unidades escolares.

Tomamos o nome Projeto de Formação Docente na Escola do R3 como paráfrase de lócus de formação continuada, por significar a ambiência escolar em que se dá a formação continuada de professores. Conforme Guimarães, "se se mudam os lugares enunciativos em confronto, recortam-se outros campos de 'objetos' relativos a um dizer" (GUIMARÃES, 2001, p. 47).

Diferentemente da designação Projeto Sala de Educador, que amplia a participação de todos os envolvidos no processo escolar, a designação Projeto de Formação Docente na Escola exclui a participação de Profissionais Técnicos e de Apoio Administrativo Educacional, instalando nessa enunciação um novo conflito. Guimarães define o conflito como aquele que:

[...] se caracteriza pela oposição entre afirmação da igualdade em conflito com uma divisão desigual do real produzida enunciativamente pelas instituições que o organizam: organizam os lugares sociais e suas relações, identificando-os (ou seja, atribuindo-lhes sentido), e recortam o mundo das coisas, significando-as (GUIMARÃES, 2018a, p. 50). 
Em relação ao procedimento de reescrituração textual-enunciativo, a designação do nome lócus de formação continuada é uma reescrituração por substituição de Projeto Sala de Professor (R1), Projeto Sala de Educador (R2) e Projeto de Formação Docente na Escola. Essas substituições operam como uma retomada, ou seja, uma expressão é tomada em outro texto por outra expressão. Guimarães, ao se referir sobre a reescrituração, diz que:

Os procedimentos de textualidade são procedimentos de reescrituração. Ou seja, são procedimentos pelos quais a enunciação de um texto, diz insistentemente o que já foi dito. Assim a textualidade e o sentido das expressões se constituem pelo texto por esta reescrituração infinita da linguagem em que se dá como finita pelo acontecimento (e sua temporalidade) em que se enuncia (GUIMARÃES, 2005, p. 38).

Isso significa que os nomes que designam o nome lócus de formação continuada na escola por reescrituração são significados por algo que lhes é dado pelo processo da designação. Os sentidos dos nomes são elementos que fazem parte do processo de legitimação do nome lócus de formação continuada.

\section{(R4) SECRETARIA DE ESTADO DE EDUCAÇÃO, ESPORTE E LAZER (SEDUC/MT) [...] o Pró-Escolas} Formação na Escola (Pefe) é o projeto de estudo e de intervenção pedagógica, desenvolvido pelas e nas unidades escolares, a partir de um diagnóstico situacional que permite identificar as potencialidades, necessidades e dificuldades dos estudantes de maneira a subsidiar ações formativas aos profissionais da educação básica visando à melhoria do processo de ensino-aprendizagem. O Pefe é orientado e acompanhado pelos professores formadores dos Cefapros. [...] $\mathrm{O}$ Pefe concebe que os diversos ambientes são espaços educativos, portanto, a sua abrangência contempla todos os profissionais que atuam na escola, docentes e profissionais da área 21 (SEDUC/SUFP/MT - PARECER ORIENTATIVO - 
Pró-Escolas Formação na Escola/PEFE ${ }^{6}$, 2018, p. 06, grifo nosso).

Temos nesse recorte duas cenas enunciativas, a primeira constituída por um Locutor-x, que diz do lugar social da instituição governamental representado pela Secretaria do Estado de Educação, e na segunda, pela Superintendência de Formação dos Profissionais da Educação, órgão de assessoramento da SEDUC nas questões educacionais junto às escolas, e de um alocutor-X, representado pelos profissionais da educação de Mato Grosso que atuam nas unidades escolares.

Na cena enunciativa tomamos o nome Pró-Escola Formação na Escola como paráfrase de lócus de formação continuada por significar o lócus, o espaço e a ambiência da escola em que se realiza a formação continuada dos professores.

É importante ressaltar que o recorte R4, além de ser direcionado aos professores, inclui novamente os alocutários Profissionais Técnico e de Apoio Administrativo Educacional (Área 217\%).

Nesse recorte, temos dois procedimentos de reescrituração. Vejamos:

a) a designação do nome Pró-Escola Formação na Escola é reescriturada por definição por "é o projeto de estudo e de intervenção pedagógica";

b) a designação Pró-Escola Formação na Escola é reescriturada por condensação pela sigla Pefe.

Esses procedimentos de reescrituração no texto R4 significam que o sentido é constituído pelo modo de relação de uma expressão com outras expressões do texto, pelo movimento da língua no acontecimento da enunciação.

Assim, o efeito das reescriturações, nesses textos, produz no acontecimento da enunciação algo que é dito de outro lugar. Nas palavras de Guimarães:

Trata-se de uma operação pela qual, no fio do dizer, uma expressão reporta a outra, pelos mais variados procedimentos. Ou por negar, ou por retomá-la, ou por redizê-la com outras palavras, 
ou por expandi-la ou condensá-la, etc. (GUIMAR ÃES, 2007, p. 84).

Observa-se nos recortes analisados que as designações mudam à medida que o nome lócus de formação continuada se altera, muda em atendimento às diretrizes dos projetos, projetando novas enunciações como a inclusão e a exclusão de profissionais à formação continuada.

Assim, "o sentido de um nome (sua designação) constitui-se pelas relações do nome com outras palavras" (GUIMARÃES, 2018a, p. 156). Desse modo, a relação que a linguagem constrói com o mundo não se limita ao modo de referi-lo, mas na relação com outras palavras na medida em que as identificam simbolicamente. Nesse sentido, as designações Projeto Sala do Professor, Projeto Sala do Educador, Projeto Formação Docente na Escola e Pró-Escola Formação na Escola do nome lócus de formação continuada na escola constituem uma relação com o real, enquanto uma relação tomada na história.

\section{Considerações finais}

Na perspectiva da Semântica do Acontecimento, nosso propósito foi o de analisar o procedimento de designação do lócus espaço de formação continuada, em documentos institucionais, entre os anos de 2010 a 2018. Nesse sentido, observamos, no decorrer das análises, que a designação significa o nome, não o nome na sua existência, mas significado pela linguagem numa relação com o real pela qual podemos falar dele. $\mathrm{O}$ acontecimento enunciativo propiciou ao nome uma nova temporalização, ou seja, novos sentidos no acontecimento de linguagem, da enunciação.

Por outro lado, os documentos utilizados são constituídos de uma série de enunciações anteriores e significam por um passado de enunciações, no acontecimento dos Pareceres Orientativos que, por sua vez, identificam pela designação lócus de formação continuada o espaço pedagógico da escola. No entanto, é importante lembrar que este modo de conceber a designação a distingue da referência e abre possibilidades de um novo acontecimento.

Nos acontecimentos de linguagem de cada recorte, vimos que é preciso considerar o locutor na cena enunciativa, o memorável e o espaço de enunciação em que a cena se constitui. Conforme Guimarães (2005), na cena enunciativa, estão em jogo os lugares 
sociais do locutor, papéis enunciativos, lugares de dizer. Assim, de um lado, na posição do Estado está o Locutor-x, ora predicado pelo lugar social representado pela SEDUC, ora pela SUFP, e de alocutores-x ora representados apenas pelos professores, ora por todos os profissionais que atuam nos espaços da escola, pelo processo de inclusão e também por exclusão.

O nome lócus de formação continuada significa por uma divisão e redivisão constante nos documentos institucionais. É uma redivisão que se expande e se ressignifica. Assim, a significação desta redivisão constante ocorre pelo funcionamento da língua nos acontecimentos de enunciação. O nome lócus de formação continuada marca o espaço simbólico do processo de formação de professores e dos técnicos, cujas designações também passam a identificar os profissionais da escola.

Entendemos que o processo enunciativo da designação significa, tendo em vista o confronto de lugares enunciativos no acontecimento da enunciação.

É importante destacar que o nome lócus de formação continuada é um espaço de enunciação político constituído de línguas e falantes (a Língua do Estado, a Língua Portuguesa, e coordenadores e profissionais da educação). É o espaço de funcionamento das línguas.

$\mathrm{O}$ nome lócus de formação continuada ao ser designado por Projeto Sala do Professor, Projeto Sala do Educador, Projeto Formação Docente na Escola e Pró-Escolas Formação na Escola relaciona-se com outras enunciações que dizem sobre esses nomes.

\section{Referências Bibliográficas}

BRASIL. Rede nacional de formação continuada de professores da educação básica: Orientações Gerais. Brasília: MEC/SEB, 2016.

DUCROT, O. O dizer e o dito. Trad. Eduardo Guimarães. Campinas, SP: Pontes, 1987.

FREGE, G. Lógica e filosofia da linguagem. Trad. Paulo Alcoforado. 2. ed. São Paulo: Editora da Universidade de São Paulo, 2009.

GUIMARAES, E. A linguística é uma ciência histórica? In: BRÉAL, M. Ensaio de semântica. Campinas, SP: Pontes/Educ, 1992.

GUIMARAES, E. Textualidade e enunciação. Escritos, Campinas, Labeurb, Unicamp, n. 2., 1999. Disponível em: https://www.labeurb.unicamp.br/portal/pages/pdf/escritos/Escritos2.pdf 
GUIMARAES, E. Um mapa e suas ruas. In: ORLANDI, E. Cidade atravessada: os sentidos públicos no espaço urbano. Campinas, SP: Pontes, 2001.

GUIMARAES, E. Designação e espaço de enunciação: um encontro político no cotidiano. Letras-Língua e literatura: Limites e Fronteiras, [s.l.], n. 26, p. 53-62, 2003. Disponível em:< https://periodicos.ufsm.br/letras/article/view/11880/7307> Acesso em: GUIMARAES, E. Semântica do acontecimento: um estudo enunciativo da designação. 2. ed. Campinas, SP: Pontes, 2005.

GUIMARAES, E. Domínio semântico de determinação. In: GUIMARÃES, E.; MOLLICA, M. C. (Orgs). A palavra: forma e sentido. Campinas, SP: Pontes, 2007.

GUIMARAES, E. Os limites do sentido: um estudo histórico e enunciativo da linguagem. 2. ed. Campinas, SP: Pontes, 2010.

GUIMARAES, E. Análise de texto: procedimentos, análises, ensino. Campinas, SP: Editora RG, 2011.

GUIMARAES, E. Semântica: enunciação e sentido. Campinas, SP: Pontes Editores, 2018a.

GUIMARAES, E. Relações apositivas: dinâmica dos lugares de enunciação nas relações de designação. Traços de Linguagem, Cáceres, MT, v. 2, n. 1, p. 83-94, 2018 b.

HAROCHE, C.; HENRY, P.; PÊCHEUX, M. La Sémantique et la Coupure Saussurienne: Langue, Langage, Discours. Langages, [s.l.], n. 6 (24), p. 93-106, 1971. Disponível em: <https://www.persee.fr/doc/lgge_0458726x_1971_num_6_24_2608 > Acesso em: 05/07/2019.

MATO GROSSO. Secretaria de Estado de Educação. Políticas de Formação dos Profissionais da Educação Básica de Mato Grosso. Cuiabá: MT/SEDUC, 2010a.

MATO GROSSO. Secretaria de Estado de Educação. Parecer Orientativo. Referente ao Desenvolvimento do Projeto Sala de Professor para o ano de 2010. Cuiabá: SUFP/SEDUC/MT, 2010b.

MATO GROSSO. Secretaria de Estado de Educação. Parecer Orientativo. Referente ao Desenvolvimento do Projeto Sala de Educador para o ano de 2011. Cuiabá: SUFP/SEDUC/MT, 2011.

MATO GROSSO. Secretaria de Estado de Educação. Parecer Orientativo. Referente ao desenvolvimento do Projeto de Formação Docente na Escola. Cuiabá: SUFP/SEDUC/MT, 2017. 
MATO GROSSO. Secretaria de Estado de Educação. Parecer Orientativo. Referente ao desenvolvimento do Pró-escolas Formação na Escola. Cuiabá: SUFP/SEDUC/MT, 2018.

ZATTAR, N. A corte portuguesa mudou-se ou fugiu para o Brasil. Webrevista discursividade, Campo Grande, MS, 9. ed., jan-mai, 2012.

\section{Notas}

* Doutoranda em Linguística pela Universidade do Estado de Mato Grosso (PPGL/UNEMAT). E-mail: elianedalcico@gmail.com.

** Doutora em Linguística pela Unicamp. Atualmente, atua no Programa de Pósgraduação em Linguística da Universidade Estadual do Estado de Mato Grosso/UNEMAT. Campus de Cáceres. E-mail: neuza.zattar@gmail.com.

${ }^{1}[\ldots]$ o que chamo de "frase" é um objeto teórico, entendendo por isso, que ele não pertence, para o linguista, ao domínio do observável, mas constitui uma invenção desta ciência particular, que é a gramática. $\mathrm{O}$ que o linguista pode tomar como observável é o enunciado, considerado como a manifestação particular, como a ocorrência hic et nunc de uma frase (DUCROT, 1987, p.164).

${ }^{2}$ Conforme Guimarães (2010, p. 86): "[...] único exterior a ser considerado para Frege é o dos objetos, e o dos valores de verdade."

${ }^{3}$ Lê-se Superintendência de Formação dos Profissionais da Educação.

${ }^{4}$ Criados e implantados em 1997.

5 “[...] são procedimentos pelos quais a enunciação de um texto rediz insistentemente o que já foi dito" (GUIMARÃES, 2005, p. 28).

6 "As ações formativas contempladas pelo Pró-Escola Formação-PEF, englobam projetos de formação continuada desenvolvidos de forma sistemática como PróEscolas Formação na Escola (Pefe), o Pró-Escolas Formação Cefapro (PEFC) e o PróEscolas Formação Parcerias" (2018, p.3).

${ }^{7}$ Os profissionais que compõem a área 21 , de acordo com o PARECER $\mathrm{N}^{\circ} \mathrm{CNE} / \mathrm{CEB}$ $n^{\circ} 16 / 2015$. 